\title{
Phonological Activation in Multi-syllabic Word Recognition
}

\author{
Chang H. Lee
}

Published online: 13 December 2006

(C) Springer Science+Business Media, LLC 2006

\section{Erratum to: Journal of Psycholinguistic Research DOI 10.1007/s10936-006-9029-4}

"Sord" in the title of this article as printed should be "Word".

The online version of the original article can be found at http://dx.org.doi.10.1007/s10936-006-9029-4.

C. H. Lee $(\otimes)$

Department of Psychology, Pusan National University, 30 changjeon.dong, Keumjeong-ku, Busan 609-735, Korea

e-mail: chleehoan@pusan.ac.kr 